\title{
Pengembangan SDM Pokdarwis Desa Wisata Sungai Awan Kiri melalui Clean, Health, Safety, and Environmental Sustainbility (CHSE)
}

\author{
Betti Ses Eka Polonia1, Ahmad Ravi*2 \\ 1,2Politeknik Negeri Ketapang \\ *e-mail: betti.polonia@gmail.com ${ }^{1}$, ahmad.ravi1689@gmail.com ${ }^{2}$
}

\begin{abstract}
The Ministry of Tourism and Creative Economy again held a Tourism Village Community Empowerment Program. The collaboration between the Ministry of Tourism and Creative Economy, the Ministry of Villages for Disadvantaged Regions, and Transmigration and Higher Education is one of its forms. Higher education institutions are required to carry out community service programs. One of these activities is in the form of human resource development activities involved in the management of tourism villages, namely Pokdarwis (Tourism Awareness Group). One of the human resource developments carried out is the strengthening of CHSE (Clean, Health, Safety, and Environmental Sustainability) materials. CHSE is a new program that is being socialized by the Ministry of Tourism and Creative Economy to encourage healthy and safe tourism activities in all tourism destinations. Also, with the existence of correct and adequate CHSE and health protocols, it becomes one of the attractions for tourists to visit tourist villages. This activity was attended by 25 participants from Pokdarwis (Tourism Awareness Group), Sungai Awan Kiri Tourism Village, Ketapang, West Kalimantan. This activity aims to improve the competence of human resources for managing the Sungai Awan Kiri Tourism Village which is closely related to CHSE, K3, and the implementation of health protocols that must be implemented in the New Normal era in tourist villages.
\end{abstract}

Keywords: tourist village, CHSE, pokdarwis

\begin{abstract}
Abstrak
Kementerian Pariwisata dan Ekonomi Kreatif kembali mengadakan Program Pemberdayaan Masyarakat Desa Wisata. Kerjasama Kemenparekraf, Kemendes PDTT, dan Perguruan Tinggi salah satu wujudnya. Perguruan tinggi diwajibkan untuk melakukan program pengabdian kepada masyarakat. Kegiatan ini salah satunya berupa kegiatan pengembangan SDM yang terlibat dalam pengelolaan desa wisata, yaitu Pokdarwis (Kelompok Sadar Wisata). Salah satu pengembangan SDM yang dilakukan adalah penguatan materi CHSE (Clean, Health, Safety, and Environmental Sustainbility). CHSE merupakan program baru yang disosialisasikan Kemenparekraf guna mendorong kegiatan wisata sehat dan aman di seluruh destinasi pariwisata. Selain itu dengan adanya CHSE dan protokol kesehatan yang benar dan memadai, maka menjadi salah satu daya tarik wisatawan untuk berkunjung ke desa wisata. Kegiatan ini diikuti oleh 25 peserta dari Pokdarwis (Kelompok Sadar Wisata) Desa Wisata Sungai Awan Kiri, Ketapang, Kalimantan Barat. Kegiatan ini bertujuan untuk peningkatan kompetensi SDM pengelola Desa Wisata Sungai Awan Kiri yang berkaitan erat dengan CHSE, K3, serta penerapan protokol kesehatan yang wajib diterapkan di era New Normal ini di desa wisata.
\end{abstract}

Kata kunci: desa wisata, CHSE, pokdarwis

\section{PENDAHULUAN}

Salah satu cara mempercepat pertumbuhan pembangunan antara lain dengan mengoptimalkan pembangunan yang berimbas pada kesejahteraan masyarakat (Wahyuni, 2018). Sektor periwisata merupakan sektor yang memiliki dampak pertumbuhan paling tinggi, dimana pengembangan destinasi wisata akan menghasilkan daya tarik yang mengundang wisatawan untuk datang berkunjung (Hadi \& Widyaningsih, 2020). Daya tarik tersebut dapat mengangkat keanekaragaman alam, budaya, hasil karya manusia sehingga menjadi ciri keunikan daerah masing-masing dengan wisata alam dan hasil karya manusia (Afif et al., 2018). Seiring berkembangnya daerah pariwisata maka akan membuka peluang lapangan pekerjaan, mengentaskan kemiskinan, menumbuhkan perekonomian serta tetap menjaga lingkungan (Sidiq \& Resnawaty, 2017). 
Dari tahun ke tahun, pemberdayaan masyarakat desa wisata perlu dilaksanakan dengan menerapkan pendekatan yang strategis dan efektif (Utomo \& Satriawan, 2018). Pendekatan tersebut dapat berupa sinergi antara Kementerian Pariwisata, dan Ekonomi Kreatif (Kemenparekraf) dengan lembaga/instansi lainnya. Dengan kerjasama antar lembaga tersebut dapat mewujudkan pariwisata Indonesia yang mengangkat keanekaragaman hayati dipadukan dengan budaya masyarakatnya sehingga menjadikan suatu daya tarik bagi wisatawan.

Dengan adanya desa wisata, optimalisasi pemberdayaan masyarakat pedesaan untuk mengembangkan wisata daerahnya dapat dilakukan serta masyarakat pedesaan juga dapat menikmati hasil dari pariwisata itu sendiri (Adinugraha, 2018; Afdal et al., 2019). Desa wisata juga dijadikan sebagai tempat atau wadah pemberdayaan masyarakat untuk mengembangkan desanya menjadi lebih baik (Alfiah et al., 2019). Peran serta masyarakat pedesaan dalam membangun pariwisata yang berbasis masyarakat serta berkelanjutan dapat dilaksanakan dengan pemanfaatan sumberdaya lokal guna peningkatan kesejahteraan dan taraf hidup masyarakat (Mustangin et al., 2017; Rizkianto \& Topowijono, 2018).

Pandemi COVID-19 mulai menyebar di awal tahun 2020, dimana juga berdampak luar biasa pada sektor parisiwisata. Survey yang dilakukan oleh Desa Wisata Institute mencatat bahwa 92,8\% desa wisata terdampak oleh pandemi COVID-19 sehingga penduduk desa-desa wisata tersebut tetap mempertahankan profesi aslinya. Sektor pariwisata tidak dipungkiri termasuk dalam penyumbang terbesar penghasilan masyarakat desa wisata. Hampir 99\% desa wisata di Indonesia ditutup karena kebijakan pembatasan sosial demi menahan laju penyebaran COVID-19. Hal tersebut mengakibatkan kerugian karena tidak adanya wisatawan. Namun setelah beberapa bulan bergulat dengan Pandemi COVID-19, kehidupan ekonomi masyarakat di semua sektor termasuk pariwisata mulai dibuka dan kembali bangkit. Masyarakat mulai terbiasa dengan COVID-19 dan selalu menerapkan protocol kesehatan di setiap kegiatan yang dilakukan. Pusat perdagangan dan destinasi wisata mulai dibuka. Begitu juga, desa-desa wisata yang dapat beroperasi seperti sedia kala, namun dengan tetap menerapkan protocol kesehatan demi mencegah penyebaran COVID-19.

Di tengah-tengah bangkitnya pariwisata Indonesia, Kementerian Pariwisata dan Ekonomi Kreatif (Kemenparekraf) kembali mengadakan Program Pemberdayaan Masyarakat Desa Wisata. Hal tersebut dilakukan melalui sinergi antara Kemenparekraf dengan Kemendes PDTT serta Perguruan Tinggi. Kerjasama ini dilakukan sesuai dengan kemampuan dan kebutuhan di lapangan. Faktor pendorong kerjasama ini adalah besarnya jumlah SDM yang perlu diberdayakan dan membutuhkan waktu yang relatif lama. Hal tersebut adalah keterbatasan Kemenparekraf untuk menjangkau masyarakat yang tersebar di seluruh Nusantara.

Dalam melakukan Tridarma, Perguruan tinggi diwajibkan untuk melakukan program pengabdian kepada masyarakat. Kerjasama Kemenparekraf, Kemendes PDTT, dan Perguruan Tinggi menjadi salah satu perwujudan pengabdian kepada masyarakat, bahkan dapat menjadi kesempatan untuk melakukan penelitian. Kegiatan ini dapat berupa kegiatan/ program yang diterapkan di desa-desa wisata berbasis pendampingan. Kegiatan pendampingan ini salah satunya berupa kegiatan pengembangan sumber daya manusia (SDM) yang terlibat langsung dalam pengelolaan desa wisata, yaitu Pokdarwis (Kelompok Sadar Wisata). Pengembangan SDM Pokdarwis desa-desa wisata di Indonesia berdampak signifikan kepada kemajuan dan kemandirian desa yang berkembang (Hermawan, 2016; Nurjayadi et al., 2020). Kegiatan ini dilakukan melalui pendekatan dalam pengembangan pariwisata yang melibatkan partisipasi aktif masyarakat lokal maupun Pokdarwis (Raharjo \& Sulaeman, 2019; Rosyada, 2020).

Adapun kegiatan pengembangan SDM ini dilakukan kepada Pokdarwis Desa Wisata Sungai Awan Kiri, Muara Pawan, Kabupaten Ketapang. Pengelolaan Desa Wisata Sungai Awan Kiri sudah memberdayakan masyarakat lokal, namun seiringnya waktu terjadi ketidakstabilan dalam pengelolaan, sehingga memberi kesan kurangnya pengelolaan yang matang dalam mengelola desa wisata Sungai Awan Kiri. Pengembangan SDM Pokdarwis ini dilakukan di Hotel Grand Zuri, Jl. D.I. Panjaitan, Ketapang, Kalimantan Barat. Kegiatan ini diisi oleh 7 orang Trainer 
dan diikuti oleh 30 orang anggota Pokdarwis Desa Sungai Awan Kiri. Trainer tersebut merupakan akademisi dari Politeknik Negeri Ketapang yang telah berpengalaman dalam melakukan pendampingan desa wisata.

Salah satu pengembangan SDM kepada Pokdarwis yang dilakukan adalah penguatan materi terkait CHSE (Clean, Health, Safety, and Environmental Sustainbility). CHSE merupakan program baru yang disosialisasikan Kemenparekraf guna mendorong kegiatan wisata sehat dan aman di seluruh destinasi pariwisata Indonesia. Pada hakikatnya materi yang diberikan tentang aspek-aspek yang meliputi CHSE serta penerapannya di desa wisata. Selain itu, prosedur standarisasi K3 pada wisata yang dikelola sehingga kecelakaan dapat diantisipasi dan diminimalisir (Mulasari, 2020).

Menurut Survey yang dilakukan Markplus Tourism (2020), sebesar 46,3\% responden menyatakan penerapan protocol CHSE di destinasi wisata juga termasuk aspek yang berpengaruh terhadap minat kunjungan karena memberikan efek rasa aman dan nyaman wisatawan. Dari sudut pandang wisatawan hal-hal terkait keamanan, keselamatan, dan kesehatan selama berwisata berpengaruh terhadap pilihan wisatawan terhadap tempat wisata tersebut. Terlebih lagi di masa Pandemi COVID-19, mulai dari pemakaian masker, budaya mencuci tangan dengan benar, menjaga jarak, serta berbagai macam himbauan tentang perilaku sehat di destinasi wisata (Fitriana et al., 2020).

Penguatan materi CHSE yang berkaitan langsung dengan keamanan, kesehatan, dan keselamatan wisatawan dan pelaku usaha wisata dipandang perlu dilakukan demi terciptanya pariwisata yang sehat, aman dan nyaman sesuai dengan yang diharapkan pada New Normal ini (Fitriana et al., 2020). Akademisi, sebagai salah satu pihak yang mendampingi desa wisata, wajib memahami materi CHSE (Cleanliness, Health, Safety and Environmental Sustainability) sehingga nantinya mampu membantu desa wisata dalam sosialisasi dan implementasi protokol kesehatan yang diperlukan.

\section{METODE}

Kegiatan pengembangan SDM Pokdarwis Desa Sungai Awan Kiri, Muara Pawan, Ketapang dilakukan dengan cara tatap muka namun tetap menerapkan protokol kesehatan. Kegiatan penguatan CHSE (Clean, Health, Safety, and Environmental Sustainbility) ini dilakukan dengan beberapa metode sebagai berikut.

a. Metode Sosialiasi

Paparan pada sosialisasi ini dilakukan oleh 7 trainer dari akademisi Politeknik Negeri Ketapang kepada peserta anggota Pokdarwis. Dalam paparan ini dibahas CHSE (Clean, Health, Safety, and Environmental Sustainbility) yang harus diterapkan di desa wisata. Selain itu, dibahas juga terkait contoh-contoh penerapannya di segala aspek desa wisata, seperti di homestay, tempat wisata, restoran/ tempat makan, dll.

b. Metode Tutorial

Pada sesi ini para trainer memutarkan beberapa video yang memuat contoh-contoh penerapan CHSE (Clean, Health, Safety, and Environmental Sustainbility) di desa wisata sejak mulai penjemputan, ketika berada di mobil jemputan, ketika berada di destinasi wisata, sampai tinggal di homestay desa wisata. Selain itu, ditampilkan juga beberapa video pokdarwis dan BUMDES yang sukses mengelola desa wisata sehingga terciptanya desa mandiri yang unggul dan berwawasan lokal.

c. Metode Diskusi

Pada sesi ini dilakukan untuk menguatkan pemahaman dan menggali pengalaman peserta sekaligus membahas tantangan apa saja dalam penerapan CHSE (Clean, Health, Safety, and Environmental Sustainbility) di desa wisata.

d. Metode evaluasi 
Pada sesi akhir ini dilakukan evaluasi untuk mengukur pemahaman peserta terkait materi CHSE (Clean, Health, Safety, and Environmental Sustainbility) yang telah diberikan. Selain itu, pada sesi ini peserta dapat memberikan saran dan masukan secara mengenai hal-hal selama kegiatan pengembangan SDM Pokdarwis CHSE (Clean, Health, Safety, and Environmental Sustainbility) ini.

\section{HASIL DAN PEMBAHASAN}

Kegiatan pengembangan SDM Pokdarwis Desa Wisata Sungai Awan Kiri, Muara Pawan, Ketapang ini dilakukan selama 2 hari, dimana sesi CHSE (Clean, Health, Safety, and Environmental Sustainbility) pada hari pertama. Sebelum kegiatan ini dimulai, semua peserta, trainer, dan panitia wajib mengikuti rapid test COVID-19 sebagai salah satu upaya menekan penyebaran COVID-19 dengan menerapkan protokol kesehatan. Ketika hasil tes seluruh peserta, trainer, dan panitia diketahui "non reaktif" maka kegiatan dibuka oleh Indra Setyawan, Kepala Seksi Direktorat Pengembangan SDM Kementerian Pariwisata dan Ekonomi Kreatif.

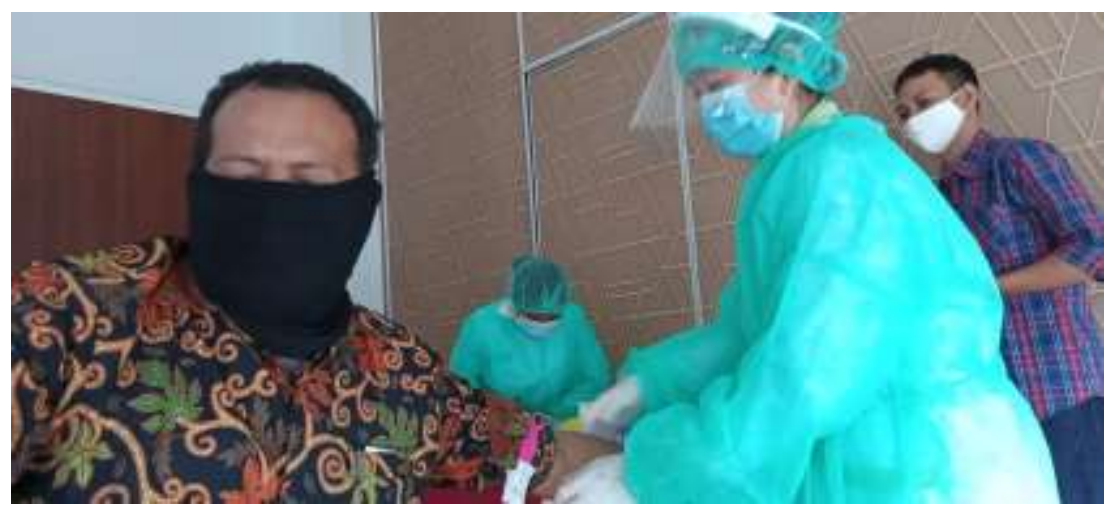

Gambar 1. Rapid test

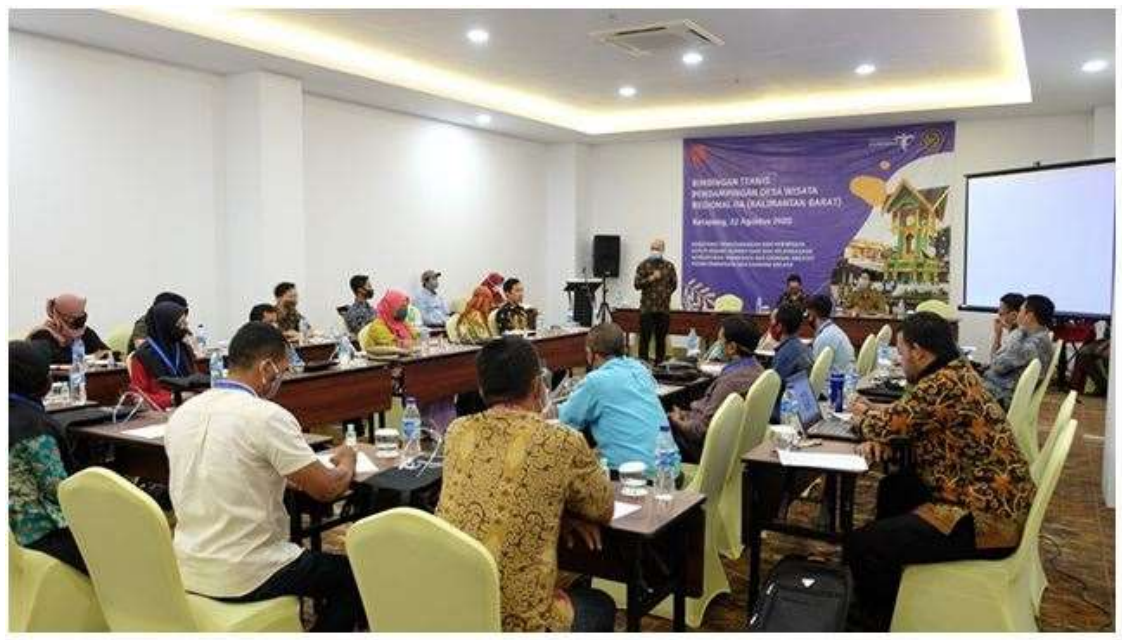

Gambar 2. Pembukaan Kegiatan oleh Perwakilan Kemenparekraf

Penguatan materi CHSE (Clean, Health, Safety, and Environmental Sustainbility) dilakukan melalui metode paparan dan tutorial selama kurang lebih 200 menit dengan diselingi diskusi dan berbagi pengalaman diantara para peserta dan trainer. Selama sesi pemaparan materi, sebagian peserta pernah mendengar dan memahami yang dimaksud dengan CHS, namun untuk aspek environmental sustainability belum memahami bahkan tidak pernah mendengarnya. CHSE (Clean, Health, Safety, and Environmental Sustainbility) bagian aspek environmental sustainability 
memang baru saja diperkenalkan dan disosialisasikan oleh Kemenparekraf kepada akademisi, kalangan industri, dan pelaku wisata secara umum.

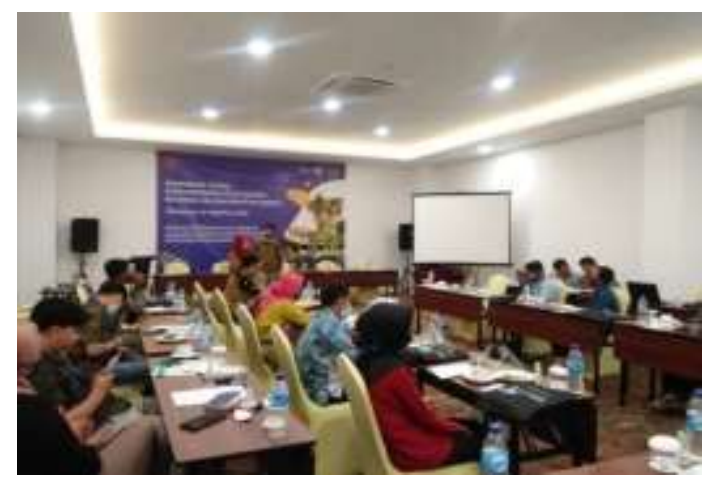

(a)

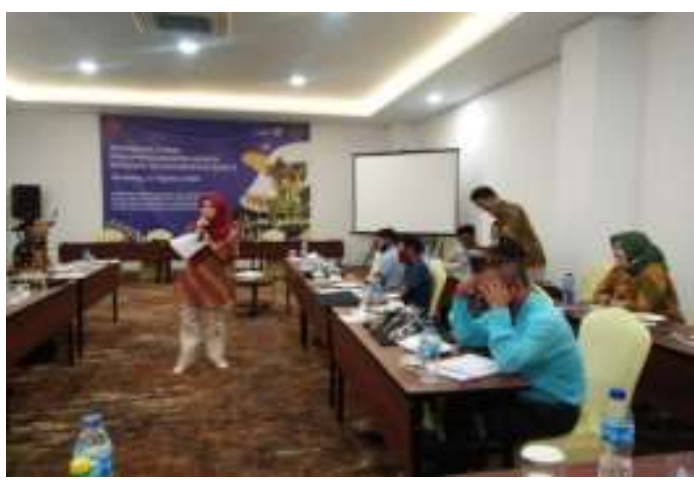

(b)

Gambar 3. Kegiatan (a) Sesi Pemaparan CHSE (b) Sesi Diskusi Kelompok Penerapan CHSE

Pada sesi selanjutnya, peserta dibagi dalam beberapa kelompok, dimana setiap kelompok terdiri dari 3 orang dan diberikan kesempatan untuk mengadakan diskusi kelompok. Diskusi tersebut mengenai penerapan CHSE (Clean, Health, Safety, and Environmental Sustainbility) di desa wisata Sungai Awan Kiri, Muara Pawan, Ketapang. Setelah diskusi selesai, untuk mengukur pemahaman peserta dilakukan evaluasi dengan kuesioner berikut kepada peserta.

a. Apakah Anda pernah mendengar tentang CHSE (Clean, Health, Safety, and Environmental Sustainbility) sebelum kegiatan ini dilakukan?

b. Apakah pemahaman tentang CHSE (Clean, Health, Safety, and Environmental Sustainbility) yang diberikan mudah dipahami dan dimengerti? Berikan tanggapan Anda.

c. Menurut Anda, dapatkan CHSE (Clean, Health, Safety, and Environmental Sustainbility) diterapkan di desa wisata binaan Anda? Jelaskan.

d. Mohon berikan saran dan masukan mengenai materi CHSE (Clean, Health, Safety, and Environmental Sustainbility) agar kedepannya kami bisa meningkatkan mutu kegiatan pelatihan ini.

Berdasarkan pertanyaan pada kuesioner tersebut didapatkan hasil sebagai berikut.

a. Sebanyak 15 orang $(60 \%)$ menyatakan bahwa pertama kali mendengarkan istilah CHSE (Clean, Health, Safety, and Environmental Sustainbility) dan 10 orang (40\%) menyatakan pernah mendengar CHS tanpa E melalui beberapa sumber. Akan tetapi, secara umum 95\% peserta menyatakan tidak asing dengan aspek kesehatan, keamanan, dan keselamatan dalam kegiatan wisata.

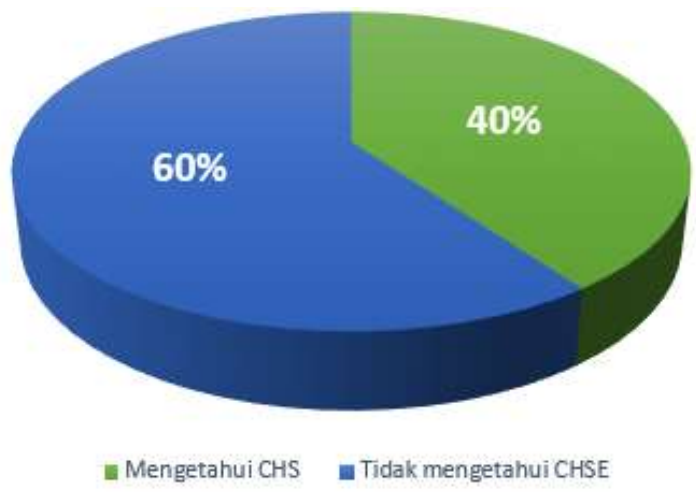

Gambar 4. Pengetahuan Peserta tentang CHSE (Clean, Health, Safety, and Environmental Sustainbility) 
b. Sebanyak 25 orang (100\%) menyatakan penyampaian CHSE (Clean, Health, Safety, and Environmental Sustainbility) mudah dipahami dan dimengerti karena disertai dengan contoh video tutorial.

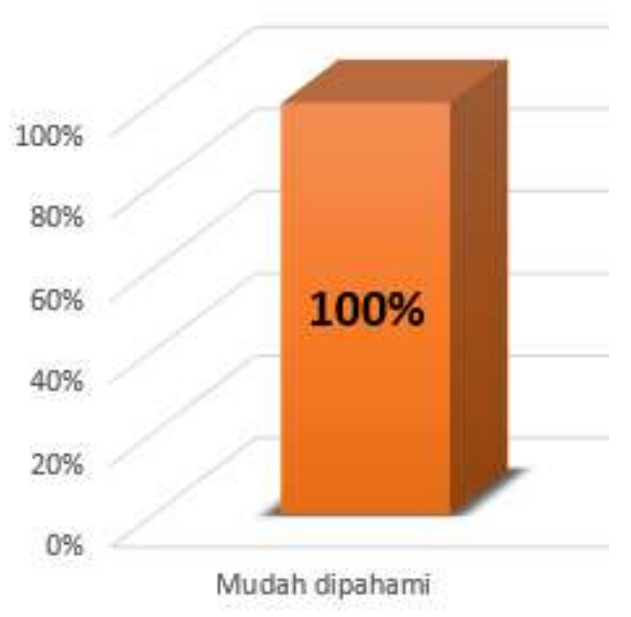

Gambar 5. Penyampaian Materi oleh Trainer

c. Sebanyak 21 orang (85\%) menyatakan CHSE (Clean, Health, Safety, and Environmental Sustainbility) dapat diterapkan di desa wisata Sungai Awan Kiri, Muara Pawan, Ketapang. Sebanyak 13 orang (55\%) meyakini keberhasilan penerapan CHSE (Clean, Health, Safety, and Environmental Sustainbility) tergantung pada masyarakat dan budaya masing-masing desa wisata untuk menggali dan memperkenalkan konsep tersebut. Berdasarkan hasil wawancara lebih lanjut, sebanyak 23 orang (95\%) menyatakan desa wisata Sungai Awan Kiri masih membutuhkan sarana dan prasarana untuk dapat mengimplementasikan CHSE (Clean, Health, Safety, and Environmental Sustainbility) seperti pada aspek ketersediaan air bersih untuk cuci tangan dan kegiatan lainnya.

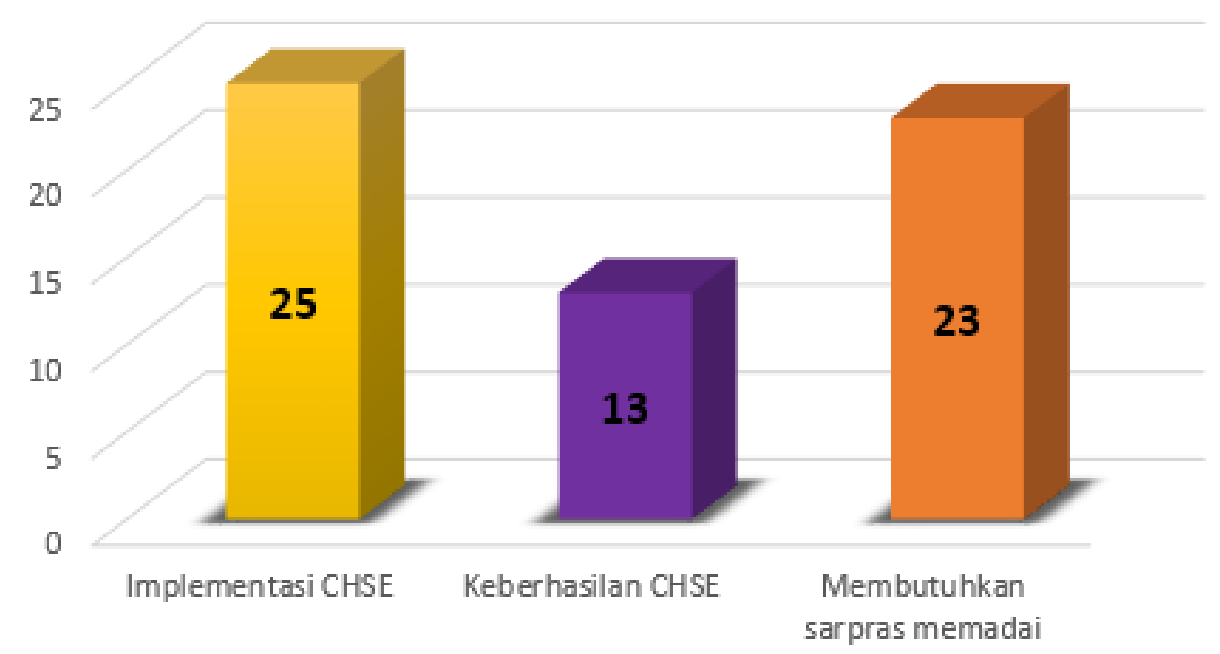

Gambar 6. Implementasi CHSE di Desa Wisata Sungai Awan Kiri, Ketapang 
d. Sebanyak 25 orang (100\%) menyatakan puas dengan kegiatan yang telah dilakukan, dimana penyampaian materi uptodate dan menyertakan contoh-contoh video. Selain itu, sebanyak 18 orang (75\%) menyatakan akan lebih baik jika kegiatan disertai dengan praktek langsung ke Desa Wisata Sungai Awan Kiri sehingga protokol kesehatan dan CHSE (Clean, Health, Safety, and Environmental Sustainbility) di dalam materi dapat diterapkan secara live di beberapa area desa wisata.

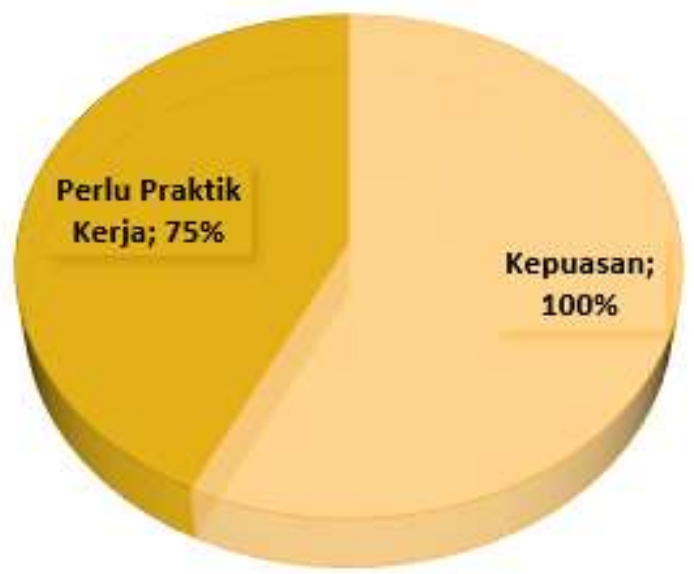

Gambar 7. Penyampaian Materi CHSE

Adapun penerapan CHSE (Clean, Health, Safety, and Environmental Sustainbility) secara terusmenerus dan berkelanjutan merupakan usaha bersama yang harus dilakukan oleh semua pihak, dimana sebagai upaya menghidupkan kembali sektor pariwisata di desa wisata. Kegiatan Pengabdian kepada Masyarakat ini juga bertujuan untuk mengajak masyarakat menerapkan kebiasaan baru untuk menekan penyebaran COVID-19 dengan sering mencuci tangan, menjaga jarak, dan memakai masker.

Dengan terlaksananya kegiatan ini diharapkan desa wisata memiliki SDM yang mampu menjadi pionir dalam penerapan protokol kesehatan, K3, serta CHSE (Clean, Health, Safety, and Environmental Sustainbility). Melalui protokol kesehatan yang benar dan memadai, maka menjadi salah satu daya tarik wisatawan untuk berkunjung ke desa wisata, khususnya Desa Wisata Sungai Awan Kiri, Ketapang. Hal ini sesuai dengan yang diungkapkan Pradono (2020), dimana faktor keamanan dan kesehatan sebagai faktor utama wisatawan memilih destinasi wisata. Selain itu, setelah terlaksananya kerjasama Kemenparekraf, Kemendes PDTT, dan Perguruan Tinggi ini, desa wisata maupun destinasi wisata lainnya dapat beroperasi kembali dan berkontribusi bagi peningkatan kesejahteraan masyarakat di desa dan juga menunjang pembangunan nasional yang merata dan menyeluruh.

\section{KESIMPULAN}

Hasil kegiatan pengembangan SDM Pokdarwis Desa Wisata Sungai Awan Kiri yang telah dilaksanakan berupa penguatan materi CHSE (Clean, Health, Safety, and Environmental Sustainbility) kepada Pokdarwis dan elemen masyarakat di Desa Wisata Sungai Awan Kiri, Ketapang, Kalimantan Barat. Hal tersebut berguna untuk peningkatan kompetensi SDM pengelola Desa Wisata Sungai Awan Kiri yang berkaitan erat dengan CHSE, K3, serta penerapan protokol kesehatan yang wajib diterapkan di era New Normal ini di desa wisata. Berdasarkan survey yang dilakukan kepada peserta kegiatan, bahwa materi yang disajikan menarik, uptodate, dan sangat dibutuhkan untuk kemajuan desa wisata yang dikelola. Peserta juga meyakini penerapan CHSE (Clean, Health, Safety, and Environmental Sustainbility) dapat menjadi suatu hal yang menarik datangnya wisatawan lokal maupun mancanegara. Saran dan masukan dari peserta supaya 
kegiatan ini dilengkapi dengan unjuk kerja langsung sebagai implementasi atas materi yang telah diberikan.

\section{UCAPAN TERIMA KASIH}

Penulis mengucapkan terima kasih kepada Direktur Politeknik Negeri Ketapang, Bapak Endang Kusmana, SE., MM., Ak.CA, dan Wadir 1 Politeknik Negeri Ketapang, Bapak Adha Panca Wardanu, S.TP., M.P serta Bapak Martanto, ST., MT selaku ketua Tim PKM Politeknik Negeri Ketapang, yang telah memberi dukungan baik berupa support serta finansial selama kegiatan ini ini berlangsung. Selain itu, tak lupa ucapan terimakasih kepada Kementerian Pariwisata dan Ekonomi Kreatif serta Pokdarwis Desa Wisata Sungai Awan Kiri yang telah mensukseskan kegiatan ini. Semoga kerjasama ini bisa terus terjalin dan dapat mewujudkan SDM Pariwisata Indonesia yang lebih maju dan berdaya saing global.

\section{DAFTAR PUSTAKA}

Adinugraha, H. H. (2018). Desa wisata halal: konsep dan implementasinya di indonesia. Human falah: Jurnal Ekonomi Dan Bisnis Islam, O(0), Article 0. http://jurnal.uinsu.ac.id/index.php/humanfalah/article/view/1336

Afif, F., Aisyianita, R. A., \& Hastuti, S. D. S. (2018). Potensi birdwatching sebagai salah satu daya tarik wisata di desa wisata jatimulyo, kecamatan girimulyo,kabupaten kulon progo. Media Wisata, 16(2), Article 2. https://doi.org/10.36276/mws.v16i2.260

Alfiah, S., Andriani, J., Lesmana, R., Sunardi, N., \& Furyanah, A. (2019). Manajemen Pengelolaan Desa Wisata Pada Desa Cimanggu, Kecamatan Cisalak, Kabupaten Subang, Privinsi Jawa Barat (Studi Kasus pada Curug Paok dan Bukit Pasir Jaka). Jurnal Abdi Masyarakat Humanis, 1(1), Article 1. https://doi.org/10.32493/\%JAMH.v1i1.3377

Amrina Rosyada. (2020). Pendampingan pembentukan badan usaha milik desa (bumdes) desa kendalasem wedung demak. Dinamisia : Jurnal Pengabdian Kepada Masyarakat, 3(2), 235-243. https://doi.org/10.31849/dinamisia.v3i2.3292

Fitriana, R., Simanjutak, D., \& Dewanti, Retno. (2020). Pembekalan materi chse (cleanliness, health, safety and environmental sustainability) dalam training of trainers untuk akademisi pendamping desa wisata. (2020). CARADDE: Jurnal Pengabdian Kepada Masyarakat, 3(1), 138-145. https://doi.org/10.31960/caradde.v3i1.539

Hadi, W., \& Widyaningsih, H. (2020). Implementasi Penerapan Sapta Pesona Wisata Terhadap Kunjungan Wisatawan Di Desa Sambirejo Kecamatan Prambanan Kabupaten Sleman Daerah Istimewa Yogyakarta. Khasanah Ilmu - Jurnal Pariwisata Dan Budaya, 11(2), 127-136. https://doi.org/10.31294/khi.v11i2.8862

Hermawan, H. (2016). Dampak Pengembangan Desa Wisata Nglanggeran Terhadap Ekonomi Masyarakat Lokal. Jurnal Pariwisata, 3(2), 105-117. https://doi.org/10.31311/par.v3i2.1383

Muhammad Afdal, Syarifuddin, H., \& Mairizal, M. (2019). Budidaya ayam-ikan terintegrasi dalam pembangunan ekonomi masyarakat desa nyogan kecamatan mestong. Dinamisia : Jurnal Pengabdian Kepada Masyarakat, 3. https://doi.org/10.31849/dinamisia.v3i0.2866

Mulasari, S. A., Izza, A. N., Masruddin, F. H., De PBMA, F., \& Axmalia, A. (2020). Pelatihan kesehatan dan keselamatan kerja (k3), service excellent, serta pengelolaan sanitasi lingkungan tempat wisata Desa Caturharjo, Pandak, Kabupaten Bantul. Jurnal Pemberdayaan: Publikasi Hasil Pengabdian Kepada Masyarakat, 4(1).

Mustangin, Kusniawati, D., Islami, N. P., Setyaningrum, B., \& Prasetyawati, E. (2017). Pemberdayaan masyarakat berbasis potensi lokal melalui program desa wisata di desa bumiaji. Sosioglobal: Jurnal Pemikiran dan Penelitian Sosiologi, 2(1), 59-72. https://doi.org/10.24198/jsg.v2i1.15282

Nurjayadi, Torkis Nasution, Herwin, \& Khusaeri Andesa. (2020). Peningkatan Pelayanan Terhadap Masyarakat Melalui Kegiatan Smart Village pada Desa Rimba Makmur Kabupaten 
Kampar. Dinamisia : Jurnal Pengabdian Kepada Masyarakat, 4(1), 140-151. https://doi.org/10.31849/dinamisia.v4i1.3224

Raharjo, T., \& Agus Sunarya Sulaeman. (2019). pembuatan rencana anggaran biaya bagi badan usaha milik desa di kabupaten tangerang. Dinamisia : Jurnal Pengabdian Kepada Masyarakat, 3(Juni). https://doi.org/10.31849/dinamisia.v3i2.2858

Rizkianto, N., \& Topowijono, T. (2018). Penerapan konsep community based tourism dalam pengelolaan daya tarik wisata berkelanjutan (studi pada desa wisata bangun, kecamatan munjungan, kabupaten trenggalek). Jurnal Administrasi Bisnis, 58(1), 20-26-26.

Sidiq, A. J., \& Resnawaty, R. (2017). Pengembangan desa wisata berbasis partisipasi masyarakat lokal di desa wisata linggarjati kuningan, jawa barat. Prosiding Penelitian dan Pengabdian kepada Masyarakat, 4(1), 38-44. https://doi.org/10.24198/jppm.v4i1.14208

Utomo, S. J., \& Satriawan, B. (2018). Strategi pengembangan desa wisata di kecamatan $\begin{array}{lllll}\text { karangploso } & \text { kabupaten } & \text { Neo-Bis, } & 11(2), & \end{array}$ https://doi.org/10.21107/nbs.v11i2.3381

Wahyuni, D. (2018). Strategi Pemberdayaan Masyarakat Dalam Pengembangan Desa Wisata Nglanggeran. Aspirasi: Jurnal Masalah-masalah Sosial, 9(1), 85-102-102. https://doi.org/10.46807/aspirasi.v9i1.994 